The Open Dentistry Journal
CrossMark
Content list available at: www.benthamopen.com/TODENTJ/
DOI: $10.2174 / 1874210601610010497$

RESEARCH ARTICLE

\title{
Effect of Finishing Time on Microleakage at the Composite-Repair Interface
}

\author{
Fereshteh Shafiei ${ }^{\mathrm{a}}$, Nazanin Berahman ${ }^{\mathrm{b}, *}$ and Elmira Niazi ${ }^{\mathrm{c}}$ \\ ${ }^{a}$ Oral and Dental Disease Research Center, Department of Operative Dentistry, School of Dentistry, Shiraz University \\ of Medical Sciences, Shiraz, Iran \\ ${ }^{b}$ Department of Orthodontics, School of Dentistry, Shiraz University of Medical sciences, Shiraz, Iran \\ ${ }^{c}$ Department of Pediatric Dentistry, School of Dentistry, Shiraz University of Medical sciences, Shiraz, Iran
}

Received: December 31, 2014

Revised: July 12, 2016

Accepted: August 10, 2016

\begin{abstract}
:
Background:

Repair is a conservative treatment of defective composite restoration. Sealing the repair interface is a critical factor to achieve successful repaired restorations.

\section{Objective:}

The aim of this study was to evaluatethe effect of three finishing times on the microleakage at the composite-repair interface.

\section{Method:}

Eighty composite specimens (Z250) were made and aged for eight weeks in water. They were randomly divided into four groups. In the control group, repairing was done with no surface treatment and using bonding agent. In groups 2 to 4 , the specimens were repaired following roughening, etching and use of Adper Single Bond, and finished immediately, after 20 minutes and after 24 hours, respectively. After thermocycling, the microleakage at the repair interface was assessed using dye-penetration technique. The results were analyzed using Kruskal-Wallis and Mann-Whitney tests $(\alpha=0.05)$.
\end{abstract}

\section{Results:}

There was a significant difference among the four groups $(\mathrm{P}<0.001)$. The control group with the highest leakage showed a significant difference with the other groups $(\mathrm{P}<0.05)$. Immediate finishing showed a significantly higher leakage compared to 20-minute and 24hour delayed finishing time $(\mathrm{P}<0.001)$. The two latter groups had no difference.

\section{Conclusion:}

Immediate finishing of the repaired restorations negatively affect the sealing at the repair interface, while 20-minute and 24-hour delayed finishing had no adverse effect on the interface sealing.

Keywords: Composite Resin, Finishing Time, Microleakage, Repair Interface.

\section{INTRODUCTION}

During the last decade, resin-based composites have become the first choice material for direct restorations. Despite a good clinical performance, as with any restorative material, composites have a limited longevity due to deterioration and degradation in the oral cavity [1,2]. A mean annular failure rate of $2.2 \%$ for composite restorations was reported. The failure can be the result of caries, fracture, discoloration, wear, and insufficient contour [3].

\footnotetext{
* Address correspondence to this author at the Department of Orthodontics, School of Dentistry, Shiraz University of Medical Sciences, Shiraz, Iran; Tel: +987138300758; E-mail: n.berahman@gmail.com
} 
Defective restorations are traditionally replaced. This long lasting procedure which is considered complex results in removal of a significant amount of sound tooth structure and possible pulp trauma [3 - 5]. Restoration repair can be applicable as a minimally invasive approach, reducing treatment time, cost, pain and possibility of the pulp injury and damage to the adjacent teeth $[5,6]$. Therefore, repair of defective restoration instead of its complete replacement can be performed when a large part of the restoration is clinically and radiographically intact, resulting in extended longevity of the restoration $[3,7]$. In a recent clinical trial, the repair has been proved to be a safe and effective treatment in the long-term [8].

In order to achieve long-term clinical successful composite repair, development of an intimate resin-to-resin attachment and sufficient interfacial bonding between the old and new composite is required during repairing procedure [9]. Although the efficacy of the repair is related to obtaining adequate bond strength at the repair interface, this bonding should be capable of preventing microleakage at the interface. This leakage leads to interfacial discoloration, compromising aesthetic appearance of the repaired restoration [4]. Additionally, this interfacial staining may represent signs of early deterioration and debonding which accelerate the restoration failure [10, 11].

The limited availability of residual free radicals for cross-linking with repairing composite on the aged restoration [12], the poor wettability of high viscous repairing composite and polymerization shrinkage during the cure of repairing composite are contributing factors to poor coupling/bonding between the old and new composites [13]. Different chemical and/or micromechanical treatments have been evaluated for establishment of high repair bond strength. The roughening of the aged surface restoration, followed by application of an intermediate bonding agent, has been indicated to enhance the repair bond strength [14 - 17]. Although several studies have evaluated the efficacy of various repair procedures through measuring the bond strength obtained at the repair interface [12 - 17], few researchers focused on the sealing at the composite repair interface $[9,18,19]$.

Recently, Celik et al. have evaluated the effects of two composite types and different bonding agents on microleakage at the repair interface of air-abraded or bur-prepared aged composite restorations. They observed little penetration at the repair interface; however, this microleakage was less than the resin-tooth interface [19].

Cavalcanti et al. have reported that different roughening surface treatments of the aged composite and even untreated surface show little or no microleakage at the repair interface. They concluded that the use of a bonding agent in all groups (the control and experimental groups) may have masked any possible treatment effects; the bonding agent may have played a main role for sealing the repair interface [9]. The same authors in another study indicated that using different bonding agents or even not using any bonding agents on air-abraded or acid-etched composite has little or no dye penetration at the repair interface [18].

It was considered that finishing procedures of repaired specimens were made after 24 hours in the cited studies [9, 18]. However, a 24-hour delay in finishing is not clinically applicable. Recontouring and finishing of the repaired restoration are usually performed immediately at the same session that the repair is done. On the other hand, some authors stated that immediate finishing could have increased the microleakage at the adhesion-tooth structure interface [20]. The finishing step of repaired restorations may affect the repair interface. Although the effects of different surface treatments on microleakage at the repair interface were evaluated, the literature lacks information on the effect of finishing time of repaired restorations on the sealing of the interface. Clinically, microleakage at the repair interface could adversely influence the performance and longevity of the repaired restoration. Therefore, this study investigated the effect of finishing time on the microleakage between the old and new composites.

\section{MATERIALS AND METHODS}

In the first part of this in vitro study, eighty composite resin specimens were made in half length of a quadrangular acrylic resin mold with an internal space of $6 \times 6 \times 2 \mathrm{~mm}$ using a removable acrylic resin spacer. Initially, half of the mold was filled with composite resin Filtek Z250, shade A1 (3M-ESPE, St. Paul, MN, USA), in a single increment Fig. (1). A glass microscope slide covered over the mold and was pressed to remove the excess composite. Each specimen was light cured through the slide for $20 \mathrm{~s}$ using a halogen light curing unit (Coltolux 75, Coltene/Whaledent AG, Altstatten, Switzerland) at $500 \mathrm{~mW} / \mathrm{cm}^{2}$ light intensity.

The tip of the curing light was kept at a 90-degree angle to the top surface, in contact with the glass to achieve maximum curing depth. After the top surface was cured, the specimens were carefully removed from the mold and then subjected to an additional light curing for $40 \mathrm{~s}$.

The specimens were stored in water at $37^{\circ} \mathrm{C}$ for eight weeks. The specimens were then divided into four groups. In 
the control group (group 1), repairing was made with no surface treatment and use of bonding agent. In groups 2 to 4 , in order to repair the surface, each specimen was roughened with high speed diamond bur and water spray. Each surface was rinsed with distilled water for $20 \mathrm{~s}$ and dried with compressed air for $10 \mathrm{~s}$. The samples were cleaned with $37 \%$ phosphoric acid gel (3M Dental Products) for $60 \mathrm{~s}$, rinsed vigorously, and then a bonding agent (Adper Single Bond, $3 \mathrm{M}$ Dental Products) was applied according to the manufacturer's instructions and light cured for $10 \mathrm{~s}$. Each specimen was then placed into the mold and the repairing composite (Z250, shade A3) was applied and cured as described above; this completed the repair procedure. Using the darker shade allowed us to better assess the repair interface.

In group 2, finishing procedures were immediately made after repair procedure completion. In group 3, finishing procedures were made 20 minutes after repair procedure completion and in group 4, they were done 24 hours after repair procedure completion. Finishing procedures were made with a decreasing abrasive sequence of aluminum oxide disks (Sof-Lex, 3M Dental Products).

The repaired specimens were removed from the mold and stored in distilled water for 24 hours. The external surfaces of each sample were sealed with two layers of nail varnish, with the exception of the side directly exposed to the light curing. They were then thermocycled for 1000 cycles between $5{ }^{\circ} \mathrm{C}$ and $55^{\circ} \mathrm{C}$ with a one minute dwelling time at each temperature, and then immersed for 24 hours in a $0.2 \%$ methylene blue solution.

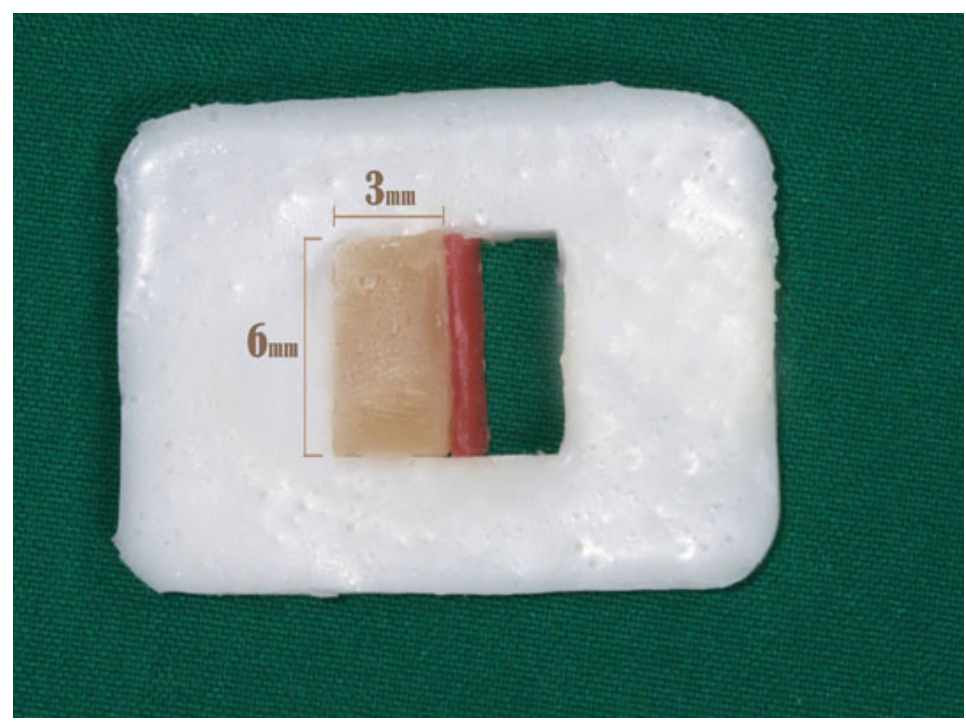

Fig. (1). Representative image showing composite specimen prepared into a mold.

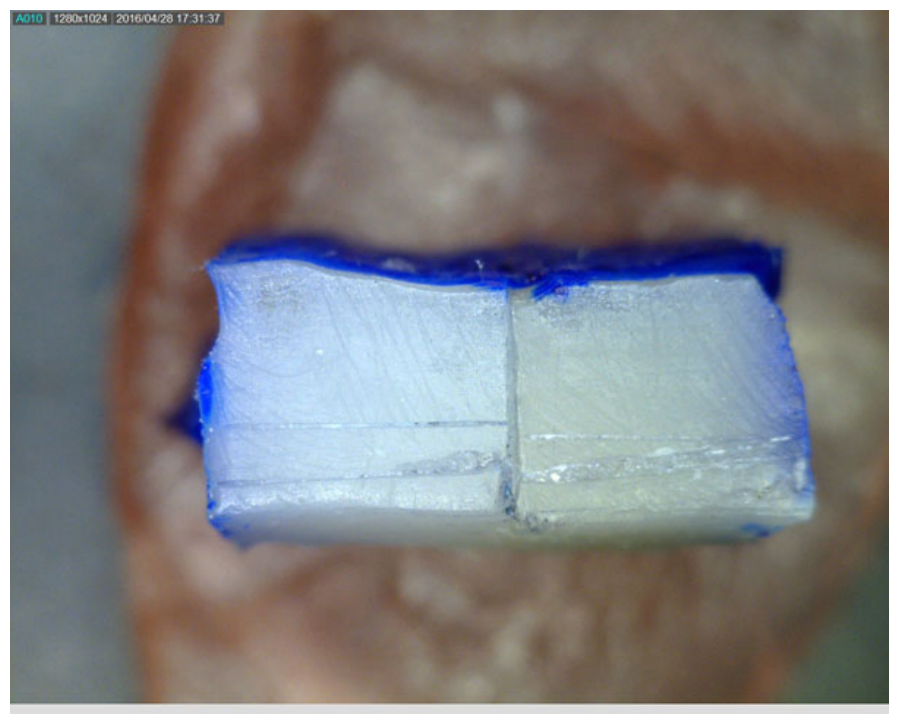

Fig. (2). Representative image showing microleakage at the repair interface. 


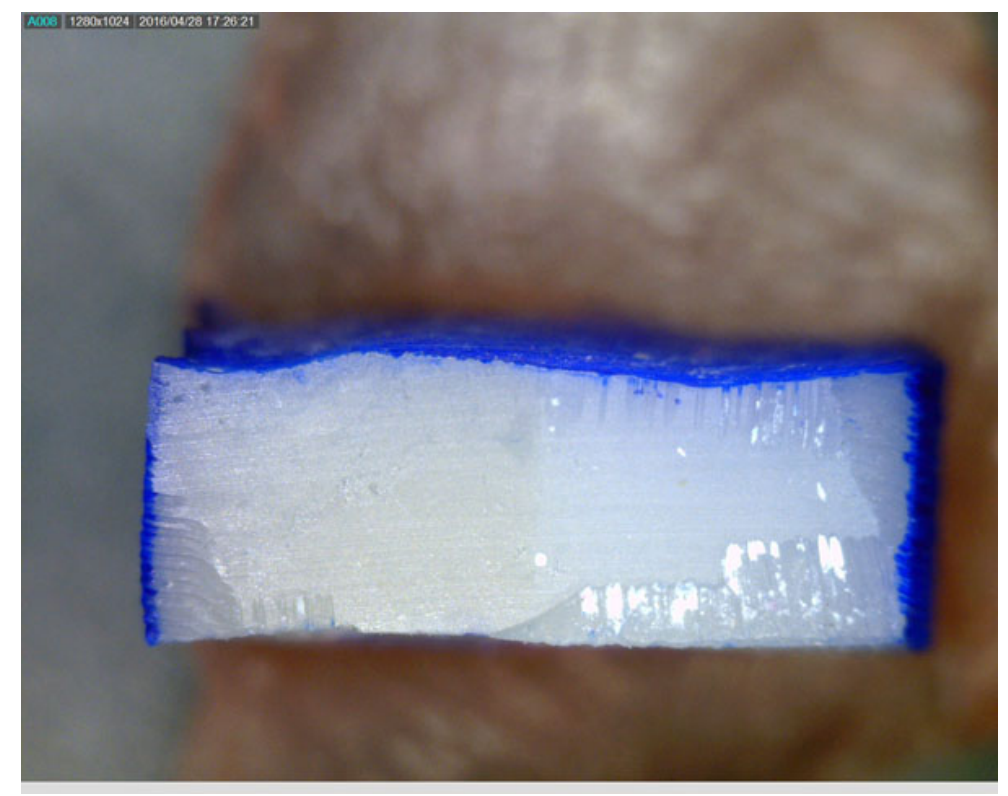

Fig. (3). Representative image showing no microleakage at the repair interface.

The samples were transversely sectioned with a double faced diamond disk. The sections were blindly assessed for the extent of dye penetration by two independent evaluators using a stereomicroscope (Carl Zeiss Inc, Oberkochen, Germany) at magnification x 20 according to the following scores:

$0=$ absence of dye penetration

$1=$ up to $1 / 2$ of repair interface

$2=$ more than $1 / 2$ of repair interface, without total involvement

$3=$ complete repair interface involvement

Data were analyzed statistically using a non parametric Kruskal-Wallis and Mann-Whitney tests at a significance level of $5 \%$.

\section{RESULTS}

Table 1 shows the microleakage scores and median scores of the four groups. According to the results of KruskalWallis test, there was a significant difference among the four groups $(\mathrm{P}<0.001)$. The control group (with no surface treatment) showed the highest leakage (Fig. 2). This group revealed the capability of dye solution for penetrating at the unsealed composite-repair interface.

Table 1. Microleakage scores frequency in the four groups.

\begin{tabular}{|l|c|c|c|c|c|c|}
\hline $\begin{array}{l}\text { Microleakage Score } \\
\text { groups }\end{array}$ & $\mathbf{0}$ & $\mathbf{1}$ & $\mathbf{2}$ & $\mathbf{3}$ & Median score & Std. deviation \\
\hline 1. Control & 0 & 1 & 17 & 2 & $2^{\mathrm{a}}$ \\
\hline 2. Immediate finishing & 3 & 7 & 9 & 1 & 0.46 \\
\hline 3. 20-min delayed finishing & 17 & 2 & - & 1 & $0.5^{\mathrm{b}}$ & $0^{\mathrm{c}}$ \\
\hline 4. 24-hour delayed finishing & 18 & 1 & 1 & - & $0^{\mathrm{c}}$ & 0.72 \\
\hline
\end{tabular}

* Different superscript letters in median column indicate statistically significant differences among groups $(p<0.05)$

Multiple comparison analysis by Mann-Whitney test showed a significant difference between group 1 and the other groups ( 1 and 2, $\mathrm{P}=0.008)$; ( 1 and $3, \mathrm{P}<0.001)$; ( 1 and $4, \mathrm{P}<0.001)$. This result indicated the beneficial effect of surface treatments used in this study compared to no treatment.

Among different finishing time groups (groups 2, 3 and 4), group 2 showed the highest leakage. There was a significant difference between groups 2 and $3(\mathrm{P}<0.001)$ and groups 2 and $4(\mathrm{P}<0.001)$. These differences demonstrated 
the adverse effect of immediate finishing on microleakage at the repair interface.

This test also revealed no differences between groups 3 and $4(\mathrm{P}=0.64)$, demonstrating similar microleakage score between 20-minute and 24-hour delayed finishing time. Fig. (3) shows no microleakage at the interface.

\section{DISCUSSION}

Proper finishing and polishing of composite restoration are important steps that improve aesthetics and longevity of the restoration [21]. These steps are also critical clinical procedures for repaired restorations. The repair of the aged composite could be done in different time periods after baseline. In the literature on the repair of composites, the most common aging method is water storage of the composite specimens for various periods ranging from one week to one year [22 - 24]. Water storage for two months was found to result in significantly lower repair bond strength than that of shorter storage time [25]. In the current study, the composites were water aged for 8 weeks prior to repairing.

Different surface treatment methods were proposed to repair the aged composites. The most frequently used method to repair are roughening of the surface with a coarse diamond bur, with silicone carbide grinding and sandblasting or air abrasion with aluminum oxide or silica-coated particles [6, 15, 22, 23, 25]. An intermediate bonding resin is usually applied on the acid etched abraded surface. In this study, a common repair technique, roughening with a diamond bur, etching with phosphoric acid followed by a bonding agent application was used $[15-17,24,26]$. This mechanical treatment is easily applied and is efficient and without less available intraoral devices in daily practice [26, 27]. The use of acid etching and rinsing as a cleaning step to remove the debris and grinding dust from the surface does not create changes in the retentive pattern of the composite's resin surface $[14,15]$. This method showed little dye penetration when finishing was done after 20 minutes and 24 hours that was similar to those of the other surface treatments used in Cavalcanti et al. study [9].

In the current study, the effect of three different finishing times on sealing the repair interface was evaluated by dye penetration technique. The immediate finishing resulted in a relatively high microleakage that was significantly lower than that of the control group (with no surface treatment) and was significantly higher than those of 20-minute and 24hour delayed finishing groups. Little leakage was observed when finishing was delayed for 20 minutes and/or 24 hours. Similarly, in two studies conducted by Cavalcanti et al., little or no dye penetration was observed at the repair interface for all the groups in which finishing was done after 24 hours [9, 18]. In these studies, the repair was performed on flat surfaces of the aged composites prepared into a mold without using tooth restoration. Our study was similar to this experimental set up.

In agreement with our results, Frankenburger et al. reported that different roughening treatments combined with adhesives and flowable composite could not totally prevent leakage at the repair interface. In a recent study, little microleakage at the repair interface was reported when using different bonding agents (except for Beauty Bond) on burand air-abraded composite. This microleakage was less than that of the tooth-interface [19]. In two subsequent studies, the repair was performed in a cavity prepared into pre-existing composite restoration and the process of the repaired restoration was finished immediately $[19,22]$.

Composites are not $100 \%$ polymerized immediately after curing. They obtain approximately $70 \%$ of the maximal polymerization after 10 to 15 minutes following light curing (dark curing) [14]. It seems that finishing procedures before complete composite maturation could have disrupted the initiated chemical and/or micromechanical bonding of the repairing composite to the aged composite. Immediate finishing could lead to plastic deformation of the composite due to thermal effect of the finishing [28]. This stress may have contributed to negative effect of early finishing on the sealing the repair interface. There is no study regarding the time at which finishing and polishing of the repaired restorations were initiated.

Considering destructive effect of finishing procedures on the marginal adaptation of newly placed composite restorations [28], some authors have suggested 24-hour delayed finishing of composite restorations [20]. However, there is controversy about finishing time on composite restorations in the literature. Yap et al. reported that one-week delayed finishing compared to immediate finishing did not improve but rather decreased the marginal sealing of the Class V composite restoration [21]. These authors explained that delayed finishing produced stresses that may compromise the seal formed by hygroscopic expansion of the bonding agent and composite [21].

However, the results of the other study revealed that 24-hour delayed wet finishing resulted in a significantly lower microleakage for microfilled composite on the dentin margin, but it had no effect on the hybrid composite [20]. The beneficial effect of 24-hour delayed finishing on marginal sealing of a microfilled composite was also reported by Irie 
et al. [29]. Nevertheless, Venturini et al. demonstrated that immediate finishing did not negatively affect the sealing ability of a microfilled and microhybrid composite [30].

According to the result of the current study, little microleakage was observed at the repair interface when finishing was delayed for 20 minutes which was in an equivalent level of microleakage of 24-hour delayed finishing. This finding could suggest that there was no reason to postpone finishing procedure for 24 hours. The finishing could be performed 20 minutes after curing at the same seating that the repair of composite restoration was done, thereby reducing the number of clinic sessions for the patient.

In the present study, the repair was done on the flat surface of the aged composite into the mold without tooth cavity involvement. This set up might mimic repairing on the composite surface alone without enamel/dentin preparation in the clinic. In in vivo situation, repair procedures can be applied with small cavity preparation in defective part of the existing restoration associated with enamel and/or dentin exposure such as repair of marginal adaptation problems. This situation may influence the microleakage at the repair interface.

Further studies should be conducted on microleakage of the repair interface at different clinical situations in which repair may be applied along with adjacent enamel or dentin involvement.

\section{CONCLUSION}

Within the limitations of this in vitro study and based on the obtained results, it can be concluded that immediate finishing negatively affected the microleakage of the composite- repair interface. The repair interface could be sealed when finishing procedures were delayed for 20 minutes and 24 hours. Therefore, repairing of a defective composite restoration can be completed in one session without compromising of the repair interface sealing.

\section{CONFLICT OF INTEREST}

The authors confirm that this article content has no conflict of interest.

\section{ACKNOWLEDGEMENTS}

The authors thank the Vice-chancellery of Shiraz University of Medical Science for supporting this research (grant \# 6655). This article is based on the thesis by Dr Berahman and Dr Niazi. The authors also thank Dr M.Vossoughi of the Dental Research Development Center, of the School of Dentistry for the statistical analysis and Dr N. Shokrpour at centre for Development of Clinical Research of Nemazee Hospital for editorial assistance.

\section{REFERENCES}

[1] Finer Y, Santerre JP. Salivary esterase activity and its association with the biodegradation of dental composites. J Dent Res 2004; 83(1): 22-6. [http://dx.doi.org/10.1177/154405910408300105] [PMID: 14691108]

[2] Manhart J, Chen H, Hamm G, Hickel R. Buonocore Memorial Lecture. Review of the clinical survival of direct and indirect restorations in posterior teeth of the permanent dentition. Oper Dent 2004; 29(5): 481-508. [PMID: 15470871]

[3] Mjör IA, Gordan VV. Failure, repair, refurbishing and longevity of restorations. Oper Dent 2002; $27(5)$ : $528-34$. [PMID: 12216574]

[4] Denehy G, Bouschlicher M, Vargas M. Intraoral repair of cosmetic restorations. Dent Clin North Am 1998; 42(4): 719-737, x. [PMID: 9891653]

[5] Burke FJ, Wilson NH, Cheung SW, Mjör IA. Influence of patient factors on age of restorations at failure and reasons for their placement and replacement. J Dent 2001; 29(5): 317-24. [http://dx.doi.org/10.1016/S0300-5712(01)00022-7] [PMID: 11472803]

[6] Hickel R, Brüshaver K, Ilie N. Repair of restorations--criteria for decision making and clinical recommendations. Dent Mater 2013; 29(1): 28-50.

[http://dx.doi.org/10.1016/j.dental.2012.07.006] [PMID: 22867859]

[7] Tyas MJ, Anusavice KJ, Frencken JE, Mount GJ. Minimal intervention dentistry--a review. FDI Commission Project 1-97. Int Dent J 2000; 50(1): 1-12.

[http://dx.doi.org/10.1111/j.1875-595X.2000.tb00540.x] [PMID: 10945174]

[8] Fernandez E, Martin J, Vildosola P, et al. Can repair increase the useful life of composite resins? Clinical trial: Triple-blind controlled - 10 
year follow-up. J Dent 2014; 14: 18-26.

[9] Cavalcanti AN, Lobo MM, Fontes CM, Liporoni P, Mathias P. Microleakage at the composite-repair interface: effect of different surface treatment methods. Oper Dent 2005; 30(1): 113-7.

[PMID: 15765966]

[10] Saunders WP. Effect of fatigue upon the interfacial bond strength of repaired composite resins. J Dent 1990; 18(3): 158-62. [http://dx.doi.org/10.1016/0300-5712(90)90059-N] [PMID: 2205638]

[11] Costa TR, Ferreira SQ, Klein-Júnior CA, Loguercio AD, Reis A. Durability of surface treatments and intermediate agents used for repair of a polished composite. Oper Dent 2010; 35(2): 231-7.

[http://dx.doi.org/10.2341/09-216-L] [PMID: 20420067]

[12] Papacchini F, Dall'Oca S, Chieffi N, et al. Composite-to-composite microtensile bond strength in the repair of a microfilled hybrid resin: effect of surface treatment and oxygen inhibition. J Adhes Dent 2007; 9(1): 25-31. [PMID: 17432398]

[13] Ivanovas S, Hickel R, Ilie N. How to repair fillings made by silorane-based composites. Clin Oral Investig 2011; 15(6): 915-22. [http://dx.doi.org/10.1007/s00784-010-0473-z] [PMID: 20953808]

[14] Papacchini F, Magni E, Radovic I, et al. Effect of intermediate agents and pre-heating of repairing resin on composite-repair bonds. Oper Dent 2007; 32(4): 363-71. [http://dx.doi.org/10.2341/06-105] [PMID: 17695609]

[15] Loomans BA, Cardoso MV, Roeters FJ, et al. Is there one optimal repair technique for all composites? Dent Mater 2011; 27(7): 701-9. [http://dx.doi.org/10.1016/j.dental.2011.03.013] [PMID: 21571359]

[16] Shahdad SA, Kennedy JG. Bond strength of repaired anterior composite resins: an in vitro study. J Dent 1998; 26(8): 685-94. [http://dx.doi.org/10.1016/S0300-5712(97)00044-4] [PMID: 9793291]

[17] Yesilyurt C, Kusgoz A, Bayram M, Ulker M. Initial repair bond strength of a nano-filled hybrid resin: effect of surface treatments and bonding agents. J Esthet Restor Dent 2009; 21(4): 251-60. [http://dx.doi.org/10.1111/j.1708-8240.2009.00271.x] [PMID: 19689724]

[18] Cavalcanti AN, Lavigne C, Fontes CM, Mathias P. Microleakage at the composite-repair interface: effect of different adhesive systems. J Appl Oral Sci 2004; 12(3): 219-22.

[http://dx.doi.org/10.1590/S1678-77572004000300011] [PMID: 21049256]

[19] Celik C, Cehreli SB, Arhun N. Resin composite repair: Quantitative microleakage evaluation of resin-resin and resin-tooth interfaces with different surface treatments. Eur J Dent 2015; 9(1): 92-9. [http://dx.doi.org/10.4103/1305-7456.149652] [PMID: 25713491]

[20] Lopes GC, Franke M, Maia HP. Effect of finishing time and techniques on marginal sealing ability of two composite restorative materials. J Prosthet Dent 2002; 88(1): 32-6. [http://dx.doi.org/10.1067/mpr.2002.127416] [PMID: 12239477]

[21] Yap AU, Ang HQ, Chong KC. Influence of finishing time on marginal sealing ability of new generation composite bonding systems. J Oral Rehabil 1998; 25(11): 871-6.

[http://dx.doi.org/10.1046/j.1365-2842.1998.00316.x] [PMID: 9846907]

[22] Frankenberger R, Krämer N, Ebert J, et al. Fatigue behavior of the resin-resin bond of partially replaced resin-based composite restorations. Am J Dent 2003; 16(1): 17-22. [PMID: 12744407]

[23] Baena E, Vignolo V, Fuentes MV, Ceballos L. Influence of repair procedure on composite-to-composite microtensile bond strength. Am J Dent 2015; 28(5): 255-60. [PMID: 26714342]

[24] Baur V, Ilie N. Repair of dental resin-based composites. Clin Oral Investig 2013; 17(2): 601-8. [http://dx.doi.org/10.1007/s00784-012-0722-4] [PMID: 22488514]

[25] Brendeke J, Ozcan M. Effect of physicochemical aging conditions on the composite-composite repair bond strength. J Adhes Dent 2007; 9(4): 399-406.

[PMID: 17847643]

[26] Bonstein T, Garlapo D, Donarummo J Jr, Bush PJ. Evaluation of varied repair protocols applied to aged composite resin. J Adhes Dent 2005; 7(1): 41-9. [PMID: 15892363]

[27] Shafiei F, Akbarian S, Daryadar M. Effect of intermediate agents and preheated composites on repair bond strength of silorane-based composites. J Dent (Tehran) 2015; 12(9): 669-77. [PMID: 27148378]

[28] Hilton TJ. Fundamentals of Operative Dentistry. $4^{\text {th }}$ Ed. Illinois US: Quintessence Publishing Co Illinois Inc 2014.

[29] Irie M, Tjandrawinata R, Suzuki K. Effect of delayed polishing periods on interfacial gap formation of Class V restorations. Oper Dent 2003; 28(5): 552-9. [PMID: 14531601] 
[30] Venturini D, Cenci MS, Demarco FF, Camacho GB, Powers JM. Effect of polishing techniques and time on surface roughness, hardness and microleakage of resin composite restorations. Oper Dent 2006; 31(1): 11-7.

[http://dx.doi.org/10.2341/04-155] [PMID: 16536188]

(C) Shafiei et al.; Licensee Bentham Open

This is an open access article licensed under the terms of the Creative Commons Attribution-Non-Commercial 4.0 International Public License (CC BY-NC 4.0) (https://creativecommons.org/licenses/by-nc/4.0/legalcode), which permits unrestricted, non-commercial use, distribution and reproduction in any medium, provided the work is properly cited. 